\title{
Application of milk thistle (Silybum marianum) in functional biscuits formulation
}

\author{
Veronika Bortlíková, Lukáš Kolarič, \\ Peter Šimko* \\ Slovak University of Technology in Bratislava, Faculty of Chemical and Food Technology, \\ Institute of Food Science and Nutrition, Radlinského 9, 81237 Bratislava, Slovak Republic \\ *qsimko@stuba.sk
}

\begin{abstract}
Due to the substantial protective effects of milk thistle to liver against various chemical compounds, a new healthy cereal product replacing wheat flour with milk thistle seed flour in the range of $5 ; 10$; 15; 20; 25 and $30 \%$ has been studied. As it has been found, milk thistle seed flour is a good source of total dietary fibre, proteins, mineral compounds and fats. During the experiments, effects of wheat flour replacement on technological properties of the dough were studied using Mixolab characteristics. From the results it can be stated that milk thistle seed flour replacement led to a decrease in water absorption and stability of dough. After baking, physical, mechanical, colour and sensorial properties of the biscuits were studied. The results have shown that even a $10 \%$ replacement results in a significant difference at $\mathrm{p}<0.05$ in measured parameters compared to ones. However, it has been calculated that statistically insignificant replacement of wheat flour with milk thistle seed flour is up to $9.3 \%$ with quality and sensorial parameters of the biscuits equal to those prepared from $100 \%$ wheat flour. Thus, production of functional biscuits at these conditions is fully possible.
\end{abstract}

Keywords: biscuits, functional foods, milk thistle, Mixolab, sensory analysis, silymarin, texture

\section{Introduction}

Over the last decades, research has proved that diets rich in fruits and vegetables are protective against the risk of some types of cancer. Several medicinal herbs have received great attention due to their wide range of pharmacological effects and also for their cancer chemopreventive activity (Ramasamy and Agarwal, 2008). Liver cancer is considered as the sixth most common cancer and the second leading cause of cancer deaths around the world (Mohammadian et al., 2018). Over 840,000 new cases of liver cancer were reported in 2018 and it was the most frequently diagnosed type of cancer in 13 countries, especially in Mongolia, Egypt or Gambia (Bray et al., 2018). Thus, there is no doubt about the increasing occurrence of liver cancer in the world. From the viewpoint of food technology, functional foods are of great interest due to their positive effects on consumer health. Functional foods are foods and their components with health benefits beyond basic nutrition; they help in maintaining health and thereby reducing the risk of diseases. Also evidence proving an association between functional foods and cancer has been reported. Flavonoids have several important biological roles associated to cancer risk. In vitro and animal model systems indicated that flavonoids influence signal transduction pathways, stimulate apoptosis and prevent inflammation and proliferation in human cancer cell lines (Aghajanpour et al., 2017).
Milk thistle (Silybum marianum) seeds (MTS) have been used for more than 2000 years as an effective medicament for liver and biliary disorders (e.g. cirrhosis, chronic hepatitis, environmental contaminants exposure) and it is one of the most common botanical supplements in the world used for therapeutic purposes (Albassam et al., 2017). According to Karkanis et al. (2011) milk thistle is an important medicinal crop in Europe especially in Poland, a significant European producer of MTS and medicines derived from it. MTS has recently become more significant in North America. According to El-haak et al. (2015), MTS contains beneficial compounds such as proteins, saccharides (especially crude fibre), minerals and some phytochemicals - mainly flavonolignans, summarily called silymarin. The main roles of this compound are liver protection, improvement of hepatocytes rearrangement, prevention of lipid peroxidation, detoxification of liver, and antioxidant activity (Tabari et al., 2019). Dried extract of MTS contains approximately $60 \%$ of silymarin (Radjabian et al., 2008). Moreover, MTS proteins have a high content of essential amino acids such as lysine, isoleucine, leucine, valine, and threonine, which are not present in wheat flour (WF) (Apostol et al., 2017a). Therefore, the application of milk thistle seed flour (MTSF) in cereal products could be beneficial due to its nutritional and health effects on consumer organism. In spite of these healthy properties, there is a lack of any information regarding the 
application of MTS in biscuits. Shahat Mohamed et al. (2016) studied replacing WF with MTSF at levels of 3, 6 and $9 \%$. According to their results, the use of MTSF at $9 \%$ did not influence the sensory properties, and therefore it is a promising way to produce low price functional bread. Apostol et al. (2017a) studied partially defatted MTSF and found that a $5 \%, 10 \%$ or even $15 \%$ replacement of WF with MTSF did not negatively affect the rheological parameters of dough used for the production of superior bakery products.

The purpose of this research is to offer new functional food which may reduce the risk of cancer, especially liver cancer. Thus, the aim of this article was to study the effects of WF replacement with 5, $10,15,20,25$ and $30 \%$ of MTSF on technological characteristics of dough and on organoleptic properties of the final product.

\section{Materials and methods}

\section{Materials}

WF (Good Mills Czech Republic s.r.o., type T530), saccharose (Korunný cukor, Slovakia), shortening (Palma a.s., Slovakia), sodium bicarbonate (Dr. Oetker s.r.o, Slovakia) and table salt (K+S Czech Republic a.s.) were purchased in a local market. MTS (Fytopharma a.s., Slovakia) was purchased in a local pharmacy. MTSF was obtained by grinding MTS using a grinder (Bosch, Germany). To obtain a uniform particle size, the MTSF was passed through a sieve with the particle size of $250 \mu \mathrm{m}$ and stored at $4^{\circ} \mathrm{C}$ in dark until usage.

\section{Chemical composition of flours}

Moisture content was determined by a modified method described by Oladunmoye et al. (2014). Temperature in the air oven was maintained at $130{ }^{\circ} \mathrm{C}$ for $60 \mathrm{~min}$. Ash content was determined by Riley et al. (2006). Crude fat content was determined by a method described by Pereira et al., (2013). Protein content was set as total nitrogen content by the Kjeldahl procedure; a factor of 6.25 was used for nitrogen conversion to crude protein in MTSF and of 5.70 in WF (Apostol et al., 2017b). Total dietary fibre (TDF) content was determined using the Megazyme International TDF assay (SunWaterhouse et al., 2010). Reducing saccharides content was determined by the Luff-Schoorl method according to Marrubini et al. (2017). Total starch content was determined using the Ewers method measuring optical rotation (Kennedy et al., 1989).

\section{Rheological properties of dough}

Rheological behaviour of dough was monitored using Mixolab 2 (Chopin Technologies, France) applying the "Chopin+" protocol, in which Mixolab recorded changes of torque in five defined points as follows: $\mathrm{C}_{1}$ - water absorption; $\mathrm{C}_{2}-$ weakening of the protein based on mechanical stress at increasing temperature; $\mathrm{C}_{3}$ - rate of starch gelatinization; $\mathrm{C}_{4}-$ stability of the formed gel; $\mathrm{C}_{5}$ - starch retrogradation during the cooling period (Švec and Hrušková, 2015). By application of the "Chopin S" protocol in Mixolab, three farinographic characteristics were measured (Kaur et al., 2016):

- dough development time (DDT); time between the first addition of water and the development of the dough's maximum consistency;

- dough stability (DS); difference in time between the point at which a top of the curve first intercepts $1.1 \mathrm{~N} \cdot \mathrm{m}$ and the point at which the top of the curves leaves the $1.1 \mathrm{~N} \cdot \mathrm{m}$ region;

- degree of softening (DoS); difference (expressed in Farinographic units - FU), between the height of the centre of the curve at the peak and the centre of the curve after $12 \mathrm{~min}$.

\section{Biscuits formulation}

Biscuits were prepared according to Kohajdová et al. (2011). The basic biscuits recipe was: $200 \mathrm{~g}$ of fine $\mathrm{WF}, 106 \mathrm{~g}$ of saccharose, $53 \mathrm{~g}$ of shortening, $2.2 \mathrm{~g}$ of sodium bicarbonate, $1.78 \mathrm{~g}$ of table salt, and $24 \mathrm{~cm}^{3}$ of water. This product was used as a reference for comparison purposes. Then, WF was replaced with MTSF at levels of 5, 10, 15, 20, 25 and $30 \%$. The cookies were round in shape and they were baked in an electric oven (Mora, Slovak Republic) at $180{ }^{\circ} \mathrm{C}$ for $8 \mathrm{~min}$.

\section{Physical properties of biscuits}

Five random biscuits were taken after baking to measure their weight $[\mathrm{g}]$, thickness $[\mathrm{mm}]$, width $[\mathrm{mm}]$ and volume $\left[\mathrm{cm}^{3}\right]$. The weight of the biscuits before and after baking was used to calculate weight loss (Ho and Abdul Latif, 2016). Spread ratio was calculated from the ratio of spread to thickness (Sindhuja et al., 2005). The volume was determined by the displacement method of millet seeds and specific volume $\left[\mathrm{cm}^{3} / 100 \mathrm{~g}\right]$ was calculated as the ratio of volume to weight (Freitas et al., 2014).

\section{Mechanical properties of biscuits}

Texture analysis of the biscuits was carried on a TA.TX.plus Texture Analyzer (Stable Micro Systems, Godalming, Surrey, U.K.). The biscuits were fractured using the three-point bending rig probe (HDP/3PB) with a $5 \mathrm{~kg}$ load cell. Experimental conditions were as follows: pre-test speed $-1.0 \mathrm{~mm} / \mathrm{s}$, test speed $-3.0 \mathrm{~mm} / \mathrm{s}$, post-test speed $-10 \mathrm{~mm} / \mathrm{s}$, distance between supports - $30 \mathrm{~mm}$ and trig- 
ger force $-50 \mathrm{~g}$. The mean maximum value was recorded as hardness $[\mathrm{g}]$ and the mean distance compressed before breaking value as fracturability [mm].

\section{Analysis of colour}

Colour of the flour mixture formulations and the upper surface colour of the biscuits were measured using a UV-VIS spectrophotometer Cary 300 (Agilent Technologies, USA); the colour itself was evaluated using the CIELAB coordinate system. The parameters measured were: $L^{*}$ (lightness factor, $0=$ black, $100=$ white $), a^{*}\left(-a^{*}=\right.$ green,$+a^{*}=$ red $)$ and $b^{*}\left(-b^{*}=\right.$ blue, $+b^{*}=$ yellow $)$. The total colour difference $(\Delta \mathrm{E})$ between the reference and the flour mixtures was calculated by Apostol et al. (2017a):

$$
\Delta E_{a b}^{*}=\sqrt{\left(\Delta L^{*}\right)^{2}+\left(\Delta a^{*}\right)^{2}+\left(\Delta b^{*}\right)^{2}}
$$

\section{Sensory evaluation}

The biscuits were subjected to sensory evaluation using nine trained panellists, men and women between the age of 22-24 years from the University community. The biscuits were analysed for their taste, aroma, crispiness, colour, hardness and overall visual acceptability on a hedonic scale going from 0 (dislike extremely) to 10 points (like extremely) (Pagès et al., 2007; Chauhan et al., 2016). Overall acceptability was expressed in percentages in the range of $0-100 \%$.

\section{Statistical analysis}

All measurements were performed in triplicate at the minimum sample amount and expressed as an average \pm standard deviation. The data were sub-
Tab. 1. Chemical composition of WF and MTSF [\%].

\begin{tabular}{lrr}
\hline Chemical component & \multicolumn{1}{c}{ WF } & \multicolumn{1}{c}{ MTSF } \\
\hline Moisture & $8.9 \pm 0.10$ & $6.0 \pm 0.10$ \\
Fat & $2.0 \pm 0.00$ & $32.9 \pm 0.10$ \\
Total dietary fibre & $2.5 \pm 0.10$ & $42.1 \pm 0.50$ \\
Starch & $67.7 \pm 0.00$ & $3.1 \pm 0.10$ \\
Reducing saccharides & $0.4 \pm 0.00$ & $1.8 \pm 0.10$ \\
Ash & $0.5 \pm 0.00$ & $5.5 \pm 0.20$ \\
Protein & $12.4 \pm 0.40$ & $20.1 \pm 0.90$ \\
\hline
\end{tabular}

All values are expressed as mean $\pm \mathrm{SD}, \mathrm{n}=3$; WF - wheat flour, MTSF - milk thistle seed flour.

jected to the Student's test using Microsoft Office Excel 365 . The obtained values were significantly different at $\mathrm{p}<0.05$. Using the Microsoft Office Excel 365, a correlation analysis was performed to determine the connection between rheological properties of dough and technological properties of supplemented biscuits, which was expressed through the Pearson correlation coefficient $(r)$. The $p$ value of highest statistically insignificant replacement in terms of overall acceptability, i.e. statistically insignificant ideal replacement, was determined by comparison.

\section{Results and Discussion}

\section{Chemical composition of flours}

Chemical composition of both flours is shown in Table 1.

The results confirmed that MTSF is a valuable source of fat, protein, and dietary fibre. In comparison to WF, MTSF contains a higher level of

Tab. 2. Rheology characteristics of dough composed of WF alone (column 1) and MTSF/ WF blends in range of $5,10,15,20,25$, and $30 \%$ (columns $2,3,4,5,6,7$ ).

\begin{tabular}{|c|c|c|c|c|c|c|c|}
\hline $\begin{array}{l}\text { Rheology } \\
\text { parameters }\end{array}$ & 1 & 2 & 3 & 4 & 5 & 6 & 7 \\
\hline WA [\%] & $57.3 \pm 0.17$ & $56.3 \pm 0.00 *$ & $55.7 \pm 0.08 *$ & $54.0 \pm 0.41 *$ & $53.1 \pm 0.05^{*}$ & $51.6 \pm 0.17 *$ & $51.2 \pm 0.08 *$ \\
\hline $\mathrm{C}_{1}[\mathrm{~N} \cdot \mathrm{m}]$ & $1.12 \pm 0.00$ & $1.09 \pm 0.01 *$ & $1.07 \pm 0.00 *$ & $1.07 \pm 0.00 *$ & $1.13 \pm 0.01$ & $1.09 \pm 0.02$ & $1.11 \pm 0.04$ \\
\hline $\mathrm{C}_{2}[\mathrm{~N} \cdot \mathrm{m}]$ & $0.55 \pm 0.01$ & $0.45 \pm 0.01 *$ & $0.31 \pm 0.01 *$ & $0.25 \pm 0.01 *$ & $0.30 \pm 0.01 *$ & $0.28 \pm 0.01 *$ & $0.28 \pm 0.01 *$ \\
\hline $\mathrm{C}_{3}[\mathrm{~N} \cdot \mathrm{m}]$ & $2.00 \pm 0.04$ & $1.66 \pm 0.02 *$ & $1.50 \pm 0.01 *$ & $1.41 \pm 0.03^{*}$ & $1.46 \pm 0.02 *$ & $1.35 \pm 0.02 *$ & $1.37 \pm 0.02 *$ \\
\hline $\mathrm{C}_{4}[\mathrm{~N} \cdot \mathrm{m}]$ & $1.99 \pm 0.04$ & $1.54 \pm 0.02 *$ & $1.48 \pm 0.02 *$ & $1.44 \pm 0.05^{*}$ & $1.55 \pm 0.02 *$ & $1.44 \pm 0.01 *$ & $1.31 \pm 0.02^{*}$ \\
\hline $\mathrm{C}_{5}[\mathrm{~N} \cdot \mathrm{m}]$ & $3.15 \pm 0.06$ & $2.59 \pm 0.04^{*}$ & $2.59 \pm 0.06^{*}$ & $2.54 \pm 0.05^{*}$ & $2.76 \pm 0.03 *$ & $2.69 \pm 0.04^{*}$ & $2.58 \pm 0.01 *$ \\
\hline DDT [min] & $4.33 \pm 0.24$ & $5.50 \pm 0.00 *$ & $6.00 \pm 0.00 *$ & $5.67 \pm 0.24 *$ & $6.33 \pm 0.24^{*}$ & $6.67 \pm 0.24 *$ & $5.83 \pm 0.48^{*}$ \\
\hline DS [min] & $18.00 \pm 0.41$ & $11.50 \pm 0.00 *$ & $8.83 \pm 1.93^{*}$ & $5.17 \pm 0.62 *$ & $5.50 \pm 0.41 *$ & $4.83 \pm 0.24 *$ & $4.50 \pm 1.41 *$ \\
\hline DoS [FU] & $17.67 \pm 3.68$ & $14.67 \pm 3.30$ & $49.00 \pm 7.26^{*}$ & $72.67 \pm 1.25^{*}$ & $69.33 \pm 5.25^{*}$ & $76.67 \pm 8.96^{*}$ & $88.33 \pm 6.24 *$ \\
\hline
\end{tabular}

All values are expressed as mean $\pm \mathrm{SD}, \mathrm{n}=3$, * indicates a statistically significant difference $(\mathrm{p}<0.05)$.

WF - wheat flour, MTSF - milk thistle seed flour, WA - water absorption; $\mathrm{C}_{1}$ - initial maximum consistence during mixing; $\mathrm{C}_{2}-$ minimum value of torsion during mixing and initial heating; $\mathrm{C}_{3}-$ maximum value (peak) of torsion during heating stage; $\mathrm{C}_{4}-$ stability of hot starch paste; $\mathrm{C}_{5}$ - difference between maximum torsion after the cooling period at $50{ }^{\circ} \mathrm{C}$; DDT - dough development time; DS - dough stability; DoS - degree of softening 
fat, protein as well as TDF. However, Apostol et al. (2017b) determined the TDF content in partially defatted MTSF to be $27.2 \%$ which is significantly lower than our results. According to El-haak et al. (2015), the contents of protein, lipids and total saccharides in the seeds are in the range of $19.1-30.0 \%$, 20.0-30.0 \%, and 24.2-26.3\%, while the starch content is only $3.1 \%$ and reducing saccharides content only $1.8 \%$, which means that TDF forms the biggest part of total saccharide content in MTSF. Also, ash content in MTSF is considerably higher compared to WF. From the results of chemical composition, it can therefore be stated that MTSF is a good source of TDF in biscuits.

\section{Rheological properties of dough}

Rheological properties of dough are provided in Table 2.

Monitoring of rheological properties of dough is very important for the overall technology to estimate mechanical properties of dough and to imitate its behaviour during its processing or even to anticipate the quality of the final product (Hadnađev et al., 2014). From the obtained data it can be clearly seen that increasing addition of MTSF decreased the absorption of water (WA) in dough. These results are in contrast with those of Shahat Mohamed et al. (2016), where WA level increased with the addition of MTSF; however, they are similar to those of Apostol et al. (2017a), where WA level decreased from $60.0 \%$ (reference sample) to $58.1 \%$ (15\% MTSF). As noted by Okuda et al. (2016), lower water content increases the dough kneading time. As it follows from Table 2 , a $30 \%$ replacement significantly decreased WA, thus it can be assumed that a larger volume of water will be needed to develop dough with the same properties in comparison with the reference. $\mathrm{C}_{2}$ values, representing the weakening of protein network, decreased from $0.55 \mathrm{~N} \cdot \mathrm{m}$ to $0.25 \mathrm{~N} \cdot \mathrm{m}$ ( $15 \%$ MTSF) and then remained at approximately constant value of $0.30 \mathrm{~N} \cdot \mathrm{m}$ indicating certain compatibility level of gluten and MTSF proteins during dough formation. $\mathrm{C}_{3}$ values are connected to starch gelatinization. As shown in Table 1, MTSF is not a rich source of starch, therefore $\mathrm{C}_{3}$ values tend to decrease during the replacement of WF. From this point of view, limiting replacement of WF with MTSF is approximately $10 \%$ since $\mathrm{C}_{4}$ and $\mathrm{C}_{5}$ were not considerably affected by the WF replacement.

From Table 2, DDT of reference dough was 4.33 min while a $5 \%$ MTSF addition increased this value to $5.50 \mathrm{~min}$. At higher replacements, this time even reached $6 \mathrm{~min}$. In general, the increase of DDT indicates that higher fibre content slows down the rate of hydration and the development of gluten (Kohajdová et al., 2011). These results correspond to the study of Shahat Mohamed et al. (2016), in which DDT of reference dough was $4.5 \mathrm{~min}$ and of the dough with a MTSF addition of 3,6 and $9 \%$ it was 6,5 and 5.5 min, respectively.

As it follows from Table 2, DS values significantly decreased with the increase of MTSF addition. At large, stability of dough is attributed to protein poor in sulfhydryl groups, which normally causes dough softening or even degradation (Shahat Mohamed et al., 2016). The gluten network with is stronger and has higher resistance to shear stress at higher protein content (Kaur et al., 2016). Although MTSF contains high level of protein, higher level of fibre may weaken the gluten network. DoS increased almost five times due to WF replacement due to high fibre and fat content in MTSF, which can weaken the dough (Shahat Mohamed et al., 2016).

\section{Physical properties of biscuits}

Table 3 summarizes physical properties (weight, thickness, diameter, spread ratio, volume, speci-

Tab. 3. Physical properties of biscuits prepared from WF and WF/MTFS blends.

\begin{tabular}{|c|c|c|c|c|c|c|c|}
\hline $\begin{array}{l}\text { Level of } \\
\text { MTSF } \\
\text { addition }\end{array}$ & $\begin{array}{c}\text { Weight } \\
\text { after } \\
\text { baking }[g]\end{array}$ & $\begin{array}{c}\text { Thickness } \\
{[\mathrm{mm}]}\end{array}$ & Width $[\mathrm{mm}]$ & $\begin{array}{c}\text { Volume } \\
{\left[\mathrm{cm}^{3}\right]}\end{array}$ & $\begin{array}{c}\text { Specific } \\
\text { volume } \\
{\left[\mathrm{cm}^{3} / 100 \mathrm{~g}\right]}\end{array}$ & $\begin{array}{c}\text { Weight loss } \\
{[\%]}\end{array}$ & Spread ratio \\
\hline $0 \%$ & $7.61 \pm 0.35$ & $7.62 \pm 0.30$ & $47.88 \pm 0.47$ & $10.60 \pm 0.49$ & $139.31 \pm 4.97$ & $13.27 \pm 0.53$ & $6.29 \pm 0.24$ \\
\hline $5 \%$ & $7.39 \pm 0.37$ & $8.10 * \pm 0.21$ & $47.13 * \pm 0.31$ & $10.60 \pm 0.49$ & $143.53 \pm 5.71$ & $13.05 \pm 0.33$ & $5.82 \pm 0.17$ \\
\hline $10 \%$ & $7.47 \pm 0.30$ & $7.05 * \pm 0.11$ & $47.75 \pm 0.78$ & $11.20 * \pm 0.40$ & $150.16 \pm 6.75$ & $13.64 \pm 0.67$ & $6.77 * \pm 0.18$ \\
\hline $15 \%$ & $7.07 \pm 0.34$ & $7.34 \pm 0.30$ & $48.08 \pm 0.11$ & $11.80 * \pm 0.40$ & $167.15 * \pm 7.39$ & $13.77 \pm 0.51$ & $6.56 \pm 0.25$ \\
\hline $20 \%$ & $6.86^{*} \pm 0.10$ & $6.69 * \pm 0.25$ & $47.62 \pm 0.69$ & $11.80 * \pm 0.40$ & $172.17 * \pm 6.82$ & $14.52 * \pm 0.58$ & $7.12 * \pm 0.19$ \\
\hline $25 \%$ & $6.61 * \pm 0.30$ & $8.85 * \pm 0.33$ & $47.72 \pm 1.73$ & $11.80 * \pm 0.40$ & $178.76^{*} \pm 7.70$ & $14.76^{*} \pm 0.38$ & $5.40 * \pm 0.28$ \\
\hline $30 \%$ & $6.68 * \pm 0.32$ & $7.47 \pm 0.26$ & $49.05^{*} \pm 0.50$ & $12.20 * \pm 0.40$ & $182.85 * \pm 6.07$ & $15.72 * \pm 0.02$ & $6.57 * \pm 0.25$ \\
\hline
\end{tabular}

All values are expressed as mean $\pm \mathrm{SD}, \mathrm{n}=5$, * indicates a statistically significant difference $(\mathrm{p}<0.05)$.

WF - wheat flour, MTSF - milk thistle seed flour 
fic volume, and weight loss) of the prepared biscuits.

A significant difference $(\mathrm{p}<0.05)$ between each sample in terms of thickness, weight, volume, specific volume, weight loss, and spread ratio was observed. Average thickness of the reference sample was $7.62 \mathrm{~mm}$ while in biscuits with the addition of MTSF it varied from 8.10 to $7.47 \mathrm{~mm}$. No significant trend in thickness and width values was found, though Ho and Abdul Latif (2016) found that thickness was positively affected by the increasing level of pitaya peel flour incorporation. According to Chauhan et al. (2016), thickness and width are related to dough viscosity; lower dough viscosity causes cookies spreading at a faster rate. As found, cookies with higher spread ratio are considered to be the most desirable (Chauhan et al., 2016). In this study, the highest spread ratio was observed in biscuits with $20 \%$ of MTSF. The spread ratio of biscuits is also influenced by the water absorption value. Higher water absorption causes less water to be available for sugar dissolution and thus the initial viscosity is higher and the cookies spread less during baking (Ho and Abdul Latif, 2016). In our experiments, water absorption of biscuits increased at 25 and $30 \%$ MTSF supplementation, so the spread ratio decreased compared to a $20 \%$ MTSF addition. It was noticed that specific volume and weight loss increased with the increasing level of MTSF. The specific volume varied from $139.31 \mathrm{~cm}^{3} / 100 \mathrm{~g}$ (reference sample) to $182.85 \mathrm{~cm}^{3} / 100 \mathrm{~g}$ (30 \% of MTSF). According to Kohajdová et al. (2011), specific volume is influenced by the interaction between gluten and dietary fibre. In their research, the addition of apple fibre caused significant decrease of the specific volume of biscuits. Apple fibre contains almost similar level of dietary fibre $(46.1 \%)$ as MTSF but mostly from soluble components such as pectins. Accord- ing to results shown in Table 1 it can be stated that MTSF consists mostly of insoluble fibre and thus the specific volume of biscuits increases. Weight loss increased from $13.27 \%$ (reference sample) to $15.72 \%$ (30\% WF replacement). However, MTSF had lower water holding capacity than WF, thus more water was evaporated during baking.

\section{Mechanical properties of biscuits}

Texture results are shown in Figure 1.

Average hardness of the reference sample was $6013 \mathrm{~g}$ and it first decreased to $4108 \mathrm{~g}$ (20\% MTSF) and then increased to $5583 \mathrm{~g}$ (30\% MTSF) with the addition of MTSF. The early decrease in hardness can be attributed to the changes in gluten structure as MTSF considerably affects the formation of gluten matrix. On the other hand, hardness tends to increase with the fibre content. Similar findings have been reported by Singh et al. (2015). In their research, hardness of the high fibre and high protein biscuits varied between 1545.14 and $2298.14 \mathrm{~g}$ due to the incorporation of spirulina and sorghum flours. According to Galla et al. (2017), breaking strength of biscuits enriched with higher levels spinach powder was comparable with that of the control, which supports our findings. Hardness is also connected to fracturability, referring to the force with which the material breaks (Singh et al., 2015). Fracturability values differ in all samples but not so significantly than hardness values, $20.43 \mathrm{~mm}$ for the reference and $21.31 \mathrm{~mm}$ for $30 \% \mathrm{WF}$ addition, however, all values were almost similar.

\section{Colour analysis}

Colour is one of the main organoleptic parameters influencing the overall acceptability of food products. The effect of MTSF on flour mixtures colour is shown in Table 4.

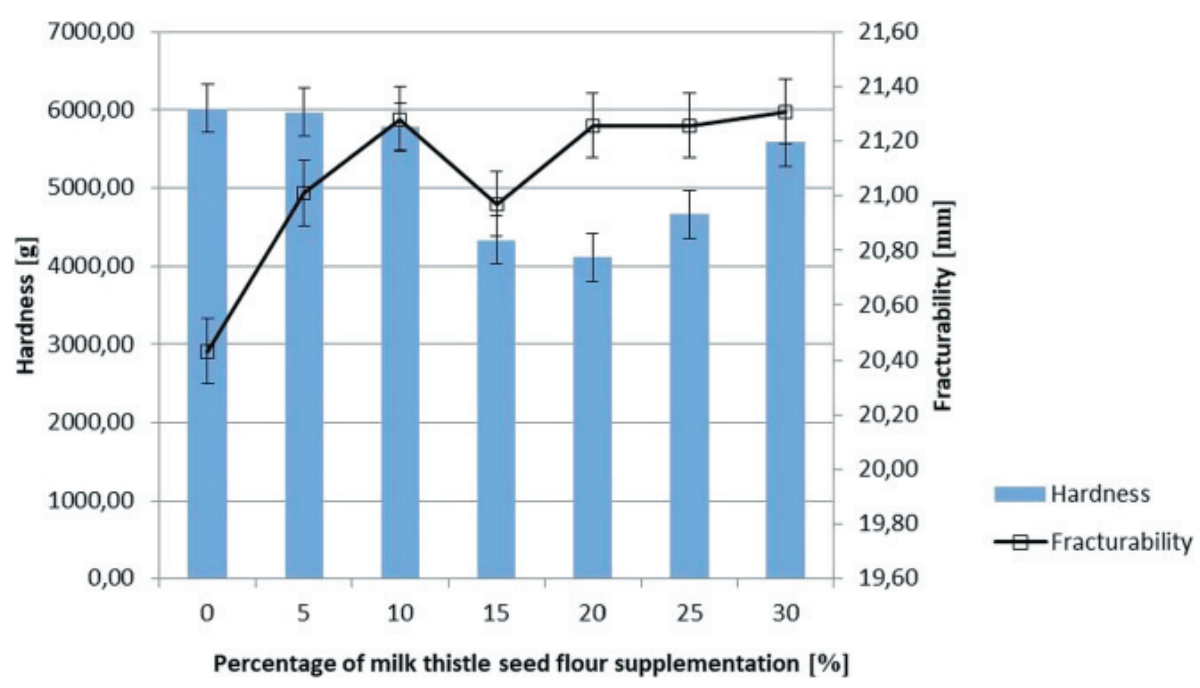

Fig. 1. Texture analysis of biscuits prepared from blends of wheat flour and milk thistle seed flour. 
Tab. 4. Colour characteristics of flour mixtures.

\begin{tabular}{lcccccccc}
\hline $\begin{array}{l}\text { Colour } \\
\text { parameter }\end{array}$ & $\mathbf{1 0 0} \mathbf{~ W F}$ & $\begin{array}{c}\mathbf{9 5} \mathbf{~ W F}+ \\
+\mathbf{5} \mathbf{~ M T S F}\end{array}$ & $\begin{array}{c}\mathbf{9 0} \mathbf{~ W F}+ \\
+\mathbf{1 0} \mathbf{~ M T S F}\end{array}$ & $\begin{array}{c}\mathbf{8 5} \mathbf{~ W F}+ \\
+\mathbf{1 5} \mathbf{~ M T S F}\end{array}$ & $\begin{array}{c}\mathbf{8 0} \mathbf{~ W F}+ \\
+\mathbf{2 0} \mathbf{~ M T S F}\end{array}$ & $\begin{array}{c}\mathbf{7 5} \mathbf{~ W F}+ \\
+\mathbf{2 5} \mathbf{~ M T S F}\end{array}$ & $\begin{array}{c}\mathbf{7 0} \mathbf{~ W F}+ \\
+\mathbf{3 0} \mathbf{M T S F}\end{array}$ & $\mathbf{1 0 0} \mathbf{M T S F}$ \\
\hline $\boldsymbol{L}^{*}$ & $84.09 \pm 0.28$ & $84.70^{*} \pm 0.16$ & $81.35^{*} \pm 0.73$ & $79.73^{*} \pm 0.63$ & $77.85^{*} \pm 0.57$ & $77.46^{*} \pm 0.66$ & $76.02^{*} \pm 0.13$ & $58.90^{*} \pm 0.34$ \\
$\boldsymbol{a}^{*}$ & $0.81 \pm 0.01$ & $0.81 \pm 0.03$ & $0.93^{*} \pm 0.05$ & $0.97^{*} \pm 0.04$ & $1.18^{*} \pm 0.02$ & $1.26^{*} \pm 0.02$ & $1.43^{*} \pm 0.01$ & $2.93^{*} \pm 0.05$ \\
$\boldsymbol{b}^{*}$ & $8.71 \pm 0.06$ & $8.25^{*} \pm 0.07$ & $8.17^{*} \pm 0.05$ & $7.76^{*} \pm 0.15$ & $8.02^{*} \pm 0.03$ & $8.32^{*} \pm 0.07$ & $8.60^{*} \pm 0.07$ & $9.16^{*} \pm 0.09$ \\
$\Delta \boldsymbol{E}_{a b}^{*}$ & - & $0.83 \pm 0.24$ & $2.79 \pm 0.72$ & $4.47 \pm 0.51$ & $6.28 \pm 0.66$ & $6.65 \pm 0.86$ & $8.09 \pm 0.29$ & $25.28 \pm 0.53$ \\
\hline
\end{tabular}

All values are expressed as mean $\pm \mathrm{SD}, \mathrm{n}=5$, * indicates a statistically significant differences $(\mathrm{p}<0.05)$.

WF - wheat flour, MTSF - milk thistle seed flour, $L^{*}-$ lightness, $a^{*}-$ redness, $b^{*}-$ yellowness, $\Delta \boldsymbol{E}_{a b}^{*}-$ colour differences

From the comparison of wheat flour and MTSF it is evident that MTSF has lower lightness parameter $\left(L^{*}=58.90\right)$ and higher redness parameter $\left(a^{*}=2.93\right)$. Yellowness parameter $\left(b^{*}=9.16\right)$ is not so different from pure WF $\left(b^{*}=8.71\right)$. Therefore, mixtures of wheat flour with MTSF have lower $L^{*}$ values and higher $a^{*}$ values. From the analysis of the total colour difference $\left(\Delta E_{a b}^{*}\right)$ it results that $5 \%$ and $10 \%$ blends are not so different from pure wheat flour with $\Delta E^{*}{ }_{a b}=0.83$ and 2.79, respectively. Other blends showed $\Delta E_{a b}^{*}$ above 3 . All values differ significantly $(\mathrm{p}<0.05)$. Apostol et al. (2017a) obtained the same results as the highest percentage of added MTSF resulted in higher redness values and lower lightness values. The colour parameters for baked products are listed in Fig. 2.

$L^{*}$ values in baked biscuits showed the same trend, i.e. the more MTSF was added, the lower lightness was observed. However, redness values were varied significantly. At first, $a^{*}$ values decreased from
3.64 (reference) to 1.87 (10\% of MTSF), probably due to melanoidin pigments formed during the Maillard reaction. Then, the effect of MTSF redness manifested and the $a^{*}$ parameter increased up to 5.00 (30\% MTSF). According to Chauhan et al. (2016), protein content is negatively correlated with the lightness of cookies, indicating that the Maillard reaction plays a major role in colour formation. The total colour difference was the lowest in biscuits with $5 \%$ of $\operatorname{MTSF}\left(\Delta E_{a b}^{*}=3.76\right)$ at $\Delta E^{*}{ }_{a b}$ of above 4 , so the colour changes were easily observed visually. Thus, biscuits enriched with MTSF do not have the same colour parameters as the reference and the replacement above $5 \%$ is not be applicable.

\section{Sensory evaluation}

The effects of WF replacement with MTSF on the sensory characteristics of biscuits are shown in Figure 3 .

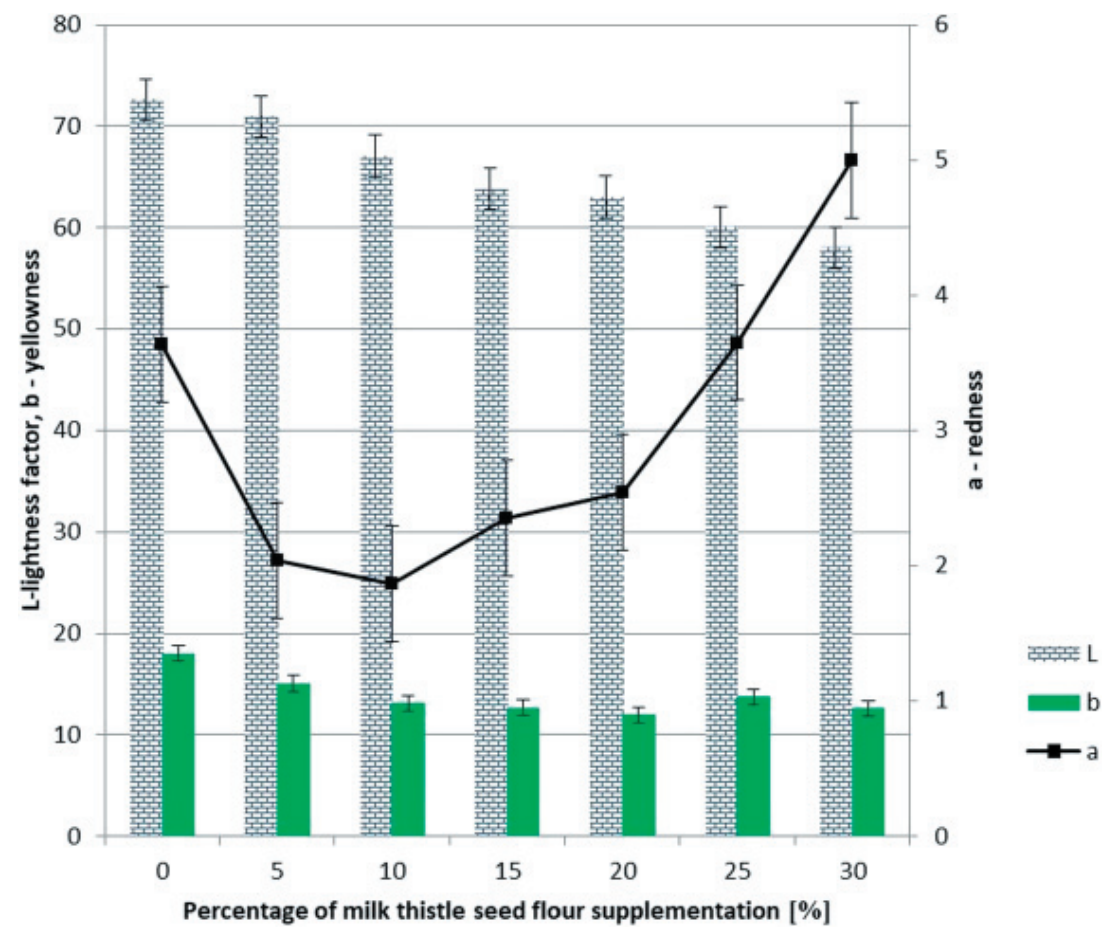

Fig. 2. Colour analysis of biscuits prepared from blends of wheat flour and milk thistle seed flour. 


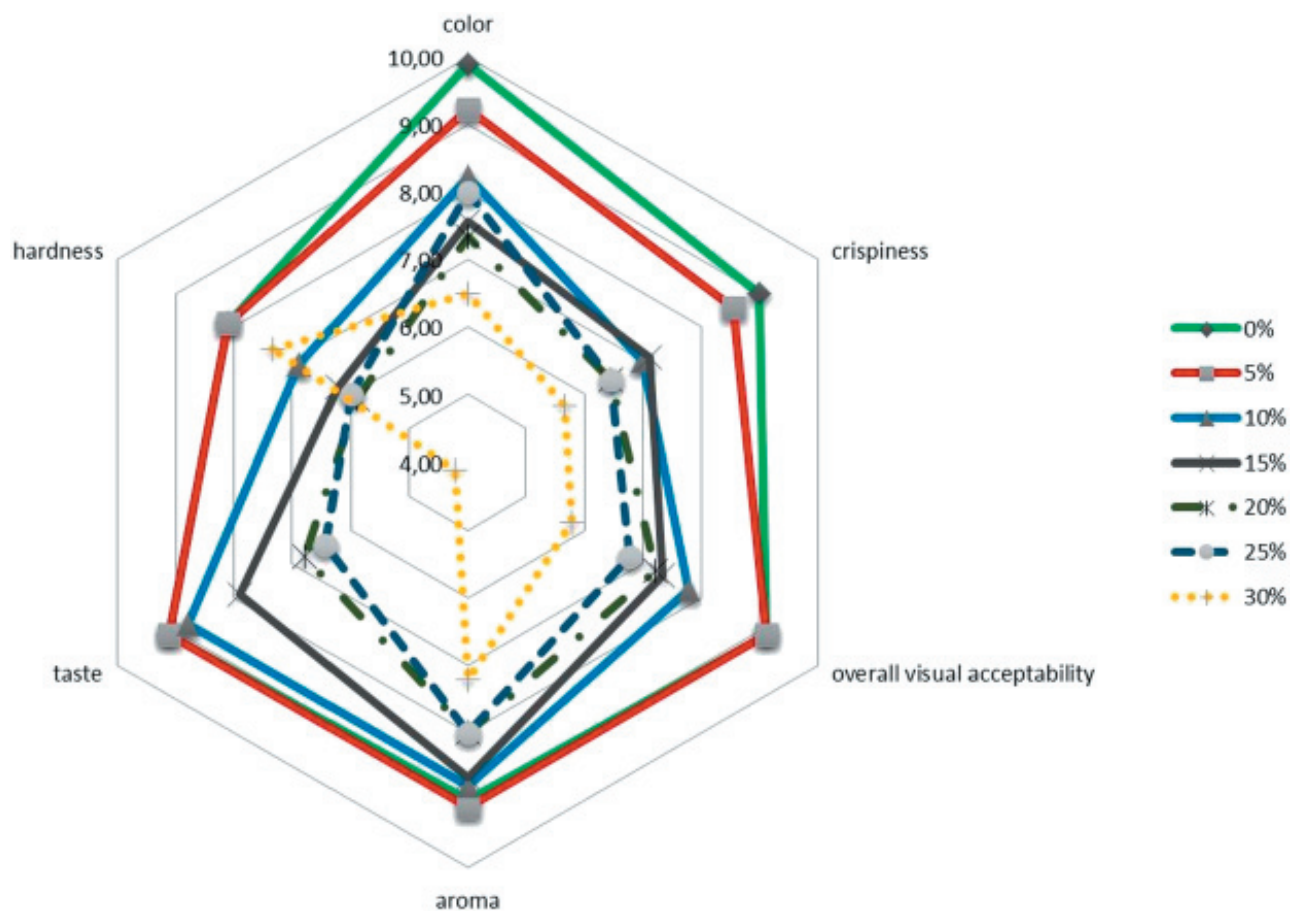

Fig. 3. Sensory evaluation of biscuits prepared from wheat flour and milk thistle seed flour blends.

A significant difference $(\mathrm{p}<0.05)$ was observed between each sample in terms of colour, crispiness, overall visual acceptability, taste and hardness while aroma showed statistically lowest difference, so this parameter is not significantly influenced by MTSF addition. All other parameters were slowly decreasing with the increasing MTFS content. According to the panellists, taste was evaluated the worst and the score dropped under 4 in biscuits with $30 \%$ MTSF. They described the products as too bitter with unnatural taste. This corresponds to higher TDF content in biscuits with the increasing MTSF content. According to Shahat Mohamed et al. (2016), changes in taste may be related to the presence of MTS seed coats which contain a high proportion of fibre (lignin). Surprisingly, the drop in colour was not so pronounced even in biscuits with $25 \%$ of MTSF; it is possible that some assessors did not consider darker colour as an issue. The sensory results of hardness corresponded with those found for the mechanical properties; they first gently decreased and then increased again. Almost similar findings were reported by Galla et al. (2017) when biscuits with $5 \%$ of spinach powder content were evaluated similarly as the control samples in all attributes. As it follows from Table 5, biscuits with a $5 \%$ replacement of WF with MTSF were the most acceptable also in these experiments since the obtained data were closest to the reference sample data.

These findings have also been confirmed by the Student's test, determining a $5 \%$ replacement as
Tab. 5. Overall acceptability of biscuits prepared from WF and WF/MTFS blends.

\begin{tabular}{lc}
\hline Level of MTSF addition & Overall acceptability [\%] \\
\hline $\mathbf{0} \%$ & $92.6 \pm 9.01$ \\
$\mathbf{5} \%$ & $91.2 \pm 5.16$ \\
$\mathbf{1 0} \%$ & $83.3 \pm 6.24^{*}$ \\
$\mathbf{1 5} \%$ & $78.3 \pm 7.45^{*}$ \\
$\mathbf{2 0} \%$ & $78.9 \pm 10.09^{*}$ \\
$\mathbf{2 5} \%$ & $67.2 \pm 13.14^{*}$ \\
$\mathbf{3 0} \%$ & $54.4 \pm 23.00^{*}$ \\
\hline
\end{tabular}

All values are expressed as mean $\pm \mathrm{SD}, \mathrm{n}=9$, * indicates a statistically significant difference $(\mathrm{p}<0.05)$.

WF - wheat flour, MTSF - milk thistle seed flour

not significant at $\mathrm{p}<0.05$, while a $10 \%$ replacement showed significant difference. Therefore, statistically insignificant replacement in terms of overall acceptability was calculated to be up to the $9.3 \%$ WF replacement.

\section{Correlation analysis}

WA of dough was significantly positively correlated with the weight of biscuits $(r=0.98)$ and negatively with the weight loss $(r=-0.93)$ and specific volume $(r=-0.99)$. DoS was on the other hand positively correlated with weight loss $(r=0.87)$ and specific volume $(r=0.96)$. Fracturability of biscuits obtained by texture analysis was negatively correlated with the Mixolab parameters $\mathrm{C}_{2}(r=-0.82), \mathrm{C}_{3}(r=-0.90), \mathrm{C}_{4}(r=-0.89)$, 
$\mathrm{C}_{5}(r=-0.79)$ and DS $(r=-0.86)$; however, positive correlation was found for DDT $(r=0.91)$. It was found that $\Delta E_{a b}^{*}$ values can be directly connected with specific volume $(r=0.96)$ and weight loss $(r=0.98)$.

\section{Conclusion}

Summarising the results and findings of this study, the following conclusions can be postulated:

4.1. MTSF is a good source of TDF, proteins, mineral compounds and fats and therefore it can be used for human nutrition. Moreover, due to the high content of flavonolignans, summarily called silymarin, and their positive effects on liver, it is also suitable for the production of functional foods. 4.2. Suitability of WF replacement with MTSF in the range of $0-30 \%$ was studied for the preparation of biscuits as healthy bakery products.

4.3. During the experiments, effects of the $\mathrm{WF}$ replacement on technological properties of the dough were determined using Mixolab characteristics. Results showed that WA gradually decreased with the increasing amount of TDF. The most influenced parameters were DS and DoS.

4.4. It has been found that WF replacement with $5 \%$ of MTSF is not significant at $\mathrm{p}<0.05$ while $10 \%$ shows a significant difference. Therefore, statistically insignificant replacement of WF with MTSF based on measured parameters was calculated as to be equal to $9.3 \%$.

4.5. Hence, the production of healthy biscuits on basis of partial WF replacement with MTSF is possible providing a new article in functional bakery products on the market.

\section{Conflict of interest}

The authors declare that they do not have any conflict of interest.

\section{Acknowledgements}

This research is the result of the project implementation "Building Infrastructure for Modern Research of Civilization's Diseases" (ITMS 26230120009), grant VEGA 1/0487/16, STU Grant scheme for Support of Young Researchers 1610 and APVV-18-0061.

\section{References}

Aghajanpour M, Nazer MR, Obeidavi Z, Akbari M, Ezati P, Kor NM (2017) American Journal of Cancer Research 7: 740-769.

Albassam AA, Frye RF, Markowitz JS (2017) ChemicoBiological Interactions, 271: 24-29.

Apostol L, Iorga S, Mosoiu C, Racovita RC, Niculae OM (2017a) Journal of International Scientific Publications 5: 74-84.
Apostol L, Iorga CS, Moşoiu C, Mustățea G, Cucu Ş (2017b) Scientific Bulletin. Series F. Biotechnologies 21: 165-169.

Bray F, Ferlay J, Soerjomataram I, Siegel RL, Torre LA, Jemal A (2018) Cancer Journal for Clinicians 68: 394-424.

Chauhan A, Saxena DC, Singh S (2016) Cogent Food \& Agriculture, 2: 1-8.

El-haak MA, Atta BM, Abd Rabo FF (2015) The Egyptian Society of Experimental Biology 11: 141-146.

Freitas CJ, Valente DR, Cruz SP (2014) Food, Nutrition \& Health, 9: 1003-1018.

Galla NR, Pamidighantam PR, Karakala B, Gurusiddaiah MR, Akula S (2017) International Journal of Gastronomy and Food Science 7: 20-26.

Hadnađev TD, Dokić L, Pojić M, Hadnađev M, Torbica A, Rakita S (2014) Hemijska Industrija 68: 99-106.

Ho LH, Abdul Latif NW (2016) Cogent Food \& Agriculture 2: 1-10.

Pereira, D, Correia PMR, Raquel PF, Guiné RPF (2013) Acta Chimica Slovaca 6: 269-280.

Karkanis A, Bilalis D, Efthimiadou A (2011) Industrial Crops and Products 34: 825-830.

Kaur A, Shevkani K, Katyal M, Singh N, Ahlawat AK, Singh, AM (2016) Journal of Food Science and Technology 53: 2127-2138.

Kennedy JF, Stevenson DL, White CA (1989) Starch/ Stärke 41: 215-221.

Kohajdová Z, Karovičová J, Jurasová M, Kukurová K (2011) Acta Chimica Slovaca 4: 88-97.

Marrubini G, Papetti A, Genorini E, Ulrici A (2017) Food Analytical Methods, 10, 1556-1567.

Mohammadian M, Mahdavifar N, MohammadianHafshejani A, Salehiniya H (2018) World Cancer Research Journal 5: 1-7.

Okuda R, Tabara A, Okusu H, Masaharu S (2016) Food Science and Technology Research 22: 841-846.

Oladunmoye OO, Aworh OC, Maziya-Dixon B, Erukainure OL, Elemo GN (2014) Food Science \& Nutrition 2: 132-138.

Pagès J, Bertrand C, Ali R, Husson F, Lè S (2007) Journal of Sensory Studies 22: 665-686.

Radjabian T, Rezazadeh SH, Fallah Huseini H (2008) Iranian Journal of Science \& Technology 32: 141-146.

Ramasamy K, Agarwal R (2008) Cancer Letters 269: 352-362.

Riley CK, Wheatley AO, Asemota HN (2006) African Journal of Biotechnology 5: 1528-1536.

Shahat Mohamed S, Hussein Ahmed S, Hady Essam A (2016) Middle East Journal of Applied Sciences, 6: 531-540.

Sindhuja A, Sudha ML, Rahim A (2005) European Food Research Technology 221: 597-601.

Singh P, Singh R, Jha A, Rasane P, Gautam AK (2015) Journal of Food Science and Technology 52: 13941403.

Sun-Waterhouse D, Teoh A, Massarotto C, Wibisono R, Wadhwa S (2010) Food Chemistry 119, 1369-1379.

Švec I, Hrušková M (2015) LWT-Food Science and Technology 60: 623-629.

Tabari SA, Carpi S, Polini B, Nieri P, Esfahani ML, Moghadamnia AA, Ghorbani H, Ranaei M, Kazemi S (2019) South African Journal of Botany 124: 494-498. 